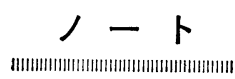

\title{
放射性医薬品による内部被曝線量に対する 不純物核種の寄与評価
}

\author{
武藤利雄 \\ 東京都立アイソトープ総合研究所 \\ 158 東京都世田谷区深沢 2-11-1 \\ 1986年 2 月 5 日 受理
}

Key Words: radiopharmaceutical, radioactive impurity, absorbed dose, MIRD procedures

\section{1. はじめに}

放射性医薬品を利用した核医学診断は核医学機器の 進歩，放射性医薬品の開発と相まって，今日の医療に 不可欠の手段として定着している1”。これに伴って， 放射性医薬品による核医学診断はX線診断とともに医 療被曝の重要な部分を占めるに至っている。このため 放射性医薬品の人体投与による患者の放射線被曝量の 軽減が望まれ, 利用される核種も ${ }^{99 \mathrm{~m}} \mathrm{Tc}$ やサイクロト ロン製造核種のような短半減期， $\beta$ 線非放出核種への 移行が進んでいる2!。これによって被曝線量は大幅に 軽減されたが ${ }^{3)}$ ，現実には使用される放射性医薬品中 に長半減期核種を含む種々の放射性核種が不純物とし て混入している。しかしながら放射性医薬品の投与に よる被暴線量の評価には, 通常, 不純物核種の存在が 考慮されていない。一部の放射性医薬品については, 不純物核種による被曝線量の寄与を指摘した報告があ るが(4)-6)，系統的な報告はない。

筆者は, in vivo 放射性核種について, 内部被曝線 量の増加, その他の品質管理の問題等の観点から現在 汎用されている ${ }^{98 \mathrm{~m}} \mathrm{Tc}^{77}$, サイクロトロン製造核種 ${ }^{8)}$, その他の製品 ${ }^{91} 12$ 種類中に含まれる不純物放射性核種 を測定し，混入核種とその濃度を明らかにした。本報 告では，これらの測定結果をもとに，不純物核種によ る内部被曝線量への寄与を計算により評価した。

\section{2. 計算 方法}

放射性医薬品の投与による体内被曝線量の評価法と して通常 MIRD 法(10) が用いられるので，本報告でも この方法に従って計算した。放射性医薬品による蔵
器・組織への被曝線量は, 投与量, 放射性核種 (RI)の物 理的性質およびその化学形などに依存する。各藏器 ・ 組織ごとに被曝線量を計算するのは容易でないので, ここでは簡単のため，体内に掑取された RI はただち に全量が全身に均等に分布するものとし, 線源蔵器

(source organ) および標的蔵器 (target organ) とも 全身とした。このような仮定のもとで算出した被曝線 量は, RI の体内分布パターンなどの生物学的パラメ 一タを考慮した結果とは多少異なるが，本報告の目的 には十分と考えられる。

一般にある時刻に和ける $\mathrm{RI}$ の体内揸取量を $I \mu \mathrm{Ci}^{*}$, $t$ 時間後における体内の残留率を $R(t)$, 体重を $m \mathrm{~g}$, 1 崩壊あたりの体内での吸収エネルギーを $と$ とる と, 全身の吸収線量は,

$$
2.134(\varepsilon / m) \cdot I \cdot R(t)[\mathrm{rad} / \mathrm{h}]
$$

となる。したがって時刻 $0-\tau$ 間の吸収線量 $D \operatorname{rad}$ は,

$$
D=2.134(\varepsilon / m) \int_{0}^{\tau} I \cdot R(t) \mathrm{d} t
$$

となる。ここで,

$$
S=2.134(\varepsilon / m)[\mathrm{rad} / \mu \mathrm{Ci} \mathrm{h}]
$$

とおくと, “ $S$ ”の值 (absorbed dose per unit cumulated activity) は詳しく計算され, MIRD パンフレットNo. $11^{11)}$ に記載されている。また，

$$
A=\int_{0}^{\tau} I \cdot R(t) \mathrm{d} t \quad[\mu \mathrm{Ci} \mathrm{h}]
$$

とおき，有効半減期を $T_{\text {eff }}$ とすると，

* MIRD法では，放射能，吸収線量などの単位とし て, 補助計量単位を使用しているので, ここでも これに谜った。 $1 \mu \mathrm{Ci}=37 \mathrm{kBq}, 1 \mathrm{mrad}=0.01 \mathrm{mGy}$ 
Table 1 Radiopharmaceuticals evaluated the absorbed dose from their impurities in this paper

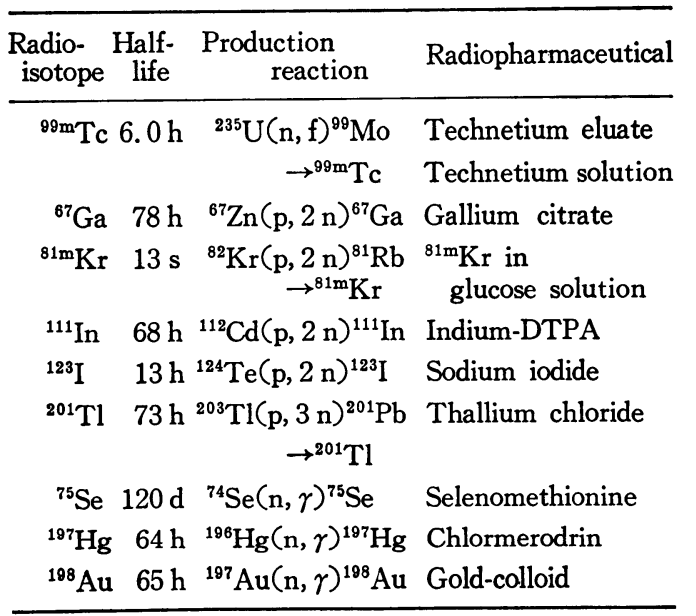

$$
\begin{aligned}
& A=\int_{0}^{\tau} I \cdot \exp \left(-\ln 2 / T_{\text {off }} \cdot t\right) \mathrm{d} t \\
& \text { となり, } \tau=\infty \text { としたときは, } \\
& A=1.441 T_{\text {orf }}
\end{aligned}
$$

となる。 $T_{\text {orf }}$ は有効半減期で, 物理的半減期と ICRP Publ. $2^{12)}$ に記載されている生物学的半減期から求め た。したがって，吸収線量 $D$ は $A$ に 值を乗ずること によって得られる。なお，MIRD パンフレットに記 載されていない核種 $\left({ }^{82 m} \mathrm{Rb}^{-82} \mathrm{Rb},{ }^{103} \mathrm{Ru}-{ }^{103 m} \mathrm{Rh}\right.$, ${ }^{110 \mathrm{~m}} \mathrm{Ag}^{110} \mathrm{Ag},{ }^{114 \mathrm{~m}} \mathrm{In}-{ }^{114} \mathrm{In},{ }^{198} \mathrm{Au},{ }^{199} \mathrm{Au},{ }^{202} \mathrm{Tl}$, その 他) については, NCRP レポート No. $58^{13)}$, その他 の文献により $S$ 値を算出した。

Table 1 には, 混入する不純物核種を実測し, それ による内部被曝線量の寄与評価の対象とした放射性医 薬品を物理的半減期および製造核反応とともに示し た。この中で, ${ }^{198} \mathrm{Au}$ は最近製造中止になって現在使 用されていないが，過去にかなりの量が使用された実 績があるので, 評価の対象とした。また, ${ }^{131} \mathrm{I}$ および ${ }^{133} \mathrm{Xe}$ 中には不純物核種の混入が認められなかったの で, 評価の対象から除外した。

\section{3. 結果と考察}

Table 2 には，各放射性医薬品の不純物核種による 内部被曝線量についての計算結果を各パラメータとと もに示した。最右欄には不純物核種による全身被曝線 量への寄与を, 目的核種による被曝線量を 1 としたと きの相対値で示した。ここで，不純物核種の混入割合 は, その実測值がメーカーごと, ロットごとに幅があ
るため比較的高い製品の值をその代表值とし, 目的核 種 $1 \mathrm{mCi}$ 当たりの $\mu \mathrm{Ci}$ 数で示した。また, ${ }^{81 \mathrm{~m}} \mathrm{Kr}$ の 場合は, 30秒間の持続注入法によって投与するものと してS值を計算した。

${ }^{{ }^{99} \mathrm{~m}} \mathrm{Tc}$ ジェネレータ溶離液には親核種の ${ }^{99} \mathrm{Mo}$ のほ か， 3 種の核分裂生成物が不純物として混入している が，これらの不純物核種による吸収線量は ${ }^{90 \mathrm{~m}} \mathrm{Tc} 37$ $\mathrm{MBq}(1 \mathrm{mCi})$ の投与に対して合計 $6.3 \times 10^{-5} \mathrm{mGy}$ $\left(6.3 \times 10^{-3} \mathrm{mrad}\right)$ で, ${ }^{99 \mathrm{~m}} \mathrm{Tc} 37 \mathrm{MBq}(1 \mathrm{mCi})$ による 吸収線量 $0.14 \mathrm{mGy}(14 \mathrm{mrad})$ に比べてかなり低い。 また, ${ }^{99 \mathrm{~m}} \mathrm{Tc}$ 溶液中には中性子捕獲反応によって生成 したと思われる不純物核種が多く混入しているが，こ

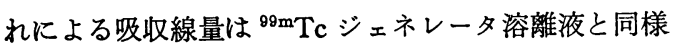
無視できる程度である。

${ }^{67} \mathrm{Ga}$ 中には比較的半減期の長い ${ }^{65} \mathrm{Zn}$ が混入してい るが，濃度が低いため，これによる吸収線量は非常に 低い。

${ }^{111} \mathrm{In},{ }^{201} \mathrm{Tl}$ 中には目的核種の同位体が比較的高濃度 で混入しており，これによる吸収線量も若干高くな り，不純物による被曝線量への寄与率も2-4\%程度 となる。

${ }^{123} \mathrm{I}$ には主に ${ }^{124} \mathrm{I},{ }^{125} \mathrm{I},{ }^{126} \mathrm{I}$ の 3 種の同位体が混入し ておりとくに ${ }^{124} \mathrm{I}$ の濃度が高い。これらの不純物に よる吸収線量は, ${ }^{123} \mathrm{I} 37 \mathrm{MBq}(1 \mathrm{mCi})$ の投与で 0.58 $\mathrm{mGy}$ (58 mrad) に対して, 合計 $1.64 \mathrm{mGy}$ (164 mrad) となり，不純物の寄与率としては約 $280 \%$ とかり高 w。

${ }^{81 \mathrm{~m}} \mathrm{Kr}$ には親核種の ${ }^{81} \mathrm{Rb}$ とその同位体が混入してお り $\left({ }^{79} \mathrm{Kr}\right.$ は ${ }^{79} \mathrm{Rb}$ (半減期23分) の $\beta^{+}$(EC) 崩壊によ って生成したもの), これらの不純物核種による吸収

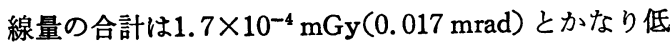
いが，目的核種 ${ }^{81 \mathrm{~m}} \mathrm{Kr}$ による吸収線量が30秒間持続注 入法で $37 \mathrm{MBq}(1 \mathrm{mCi})$ 当たり $3.1 \times 10^{-4} \mathrm{mGy}(0.031$ mrad）と低いため，その寄与率としては55\%となり， 相対的に高くなる。

${ }^{197} \mathrm{Hg}$ では, ${ }^{203} \mathrm{Hg},{ }^{60} \mathrm{Co},{ }^{65} \mathrm{Zn},{ }^{110 \mathrm{~m}} \mathrm{Ag}^{-{ }^{110}} \mathrm{Ag}$ の 4 核 種が混入しており，この中で ${ }^{203} \mathrm{Hg}$ の濃度が比較的高 い。これらの不純物核種による吸収線量は $0.01 \mathrm{mGy}$ ( $1 \mathrm{mrad})$, 寄与率は0.4\%程度である。

${ }^{75} \mathrm{Se}$ には ${ }^{110 \mathrm{~m}} \mathrm{Ag}^{-110} \mathrm{Ag}$ が微量混入しており，これ による吸収線量もごくわずかである。 ${ }^{198} \mathrm{Au}$ 中には ${ }^{199} \mathrm{Au}$ が比較的高濃度で混入しており，これによる吸 収線量が $0.6 \mathrm{mGy}(60 \mathrm{mrad})$ ，寄与率は $5 \%$ 程度であ る。 
Table 2 Estimated absorbed dose to total body from various pharmaceuticals and their radioactive impurities

\begin{tabular}{|c|c|c|c|c|c|c|}
\hline Nuclide & $\begin{array}{c}\text { Relative } \\
\text { activity }(\mu \mathrm{Ci})\end{array}$ & $\begin{array}{l}\text { Effective } \\
\text { half-life }\end{array}$ & $\begin{array}{c}S \text {-value } \\
(\mathrm{rad} / \mu \mathrm{Ci} \mathrm{h})\end{array}$ & $\begin{array}{l}\text { Absorbed dose } \\
(\mathrm{mrad} / \mu \mathrm{Ci})\end{array}$ & $\begin{array}{l}\text { Absorbed dose } \\
\text { (mrad) }\end{array}$ & Relative \\
\hline $\begin{array}{l}{ }^{99 \mathrm{~m}} \mathrm{Tc} \\
\quad \text { (generator elu }\end{array}$ & 1000 & $4.8 \mathrm{~h}$ & $2.0 \times 10^{-6}$ & 0.014 & 14 & 1 \\
\hline${ }^{99} \mathrm{Mo}^{-99 \mathrm{~m}} \mathrm{Tc}$ & $7.0 \times 10^{-3}$ & $43 \mathrm{~h}$ & $1.4 \times 10^{-5}$ & 0.86 & $6.0 \times 10^{-3}$ & $4.3 \times 10^{-4}$ \\
\hline${ }^{103} \mathrm{Ru}^{-103 \mathrm{~m}} \mathrm{Rh}$ & $1.5 \times 10^{-5}$ & $6.2 \mathrm{~d}$ & $6.6 \times 10^{-6}$ & 1.4 & $2.1 \times 10^{-5}$ & $1.5 \times 10^{-6}$ \\
\hline${ }^{106} \mathrm{Ru}^{-106} \mathrm{Rh}$ & $2.2 \times 10^{-6}$ & $7.2 \mathrm{~d}$ & $4.3 \times 10^{-5}$ & 11 & $2.3 \times 10^{-5}$ & $1.6 \times 10^{-6}$ \\
\hline${ }^{131} \mathrm{I}-{ }^{131 \mathrm{~m}} \mathrm{Xe}$ & $8.8 \times 10^{-5}$ & $7.7 \mathrm{~d}$ & $9.9 \times 10^{-6}$ & 2.6 & $2.3 \times 10^{-4}$ & $1.6 \times 10^{-5}$ \\
\hline $\begin{array}{l}{ }^{{ }^{99} \mathrm{~m}} \mathrm{Tc} \\
\quad \text { (Solution) }\end{array}$ & 1000 & $4.8 \mathrm{~h}$ & $2.0 \times 10^{-6}$ & 0.014 & 14 & 1 \\
\hline${ }^{99} \mathrm{Mo}^{-99 m} \mathrm{Tc}$ & $1.0 \times 10^{-5}$ & $43 \mathrm{~h}$ & $1.4 \times 10^{-5}$ & 0.98 & $9.8 \times 10^{-6}$ & $7.0 \times 10^{-7}$ \\
\hline${ }^{103} \mathrm{Ru}-{ }^{103 m} \mathrm{Rh}$ & $1.5 \times 10^{-5}$ & 148 & $6.6 \times 10^{-6}$ & 4.1 & $6.2 \times 10^{-6}$ & $4.4 \times 10^{-7}$ \\
\hline${ }^{131} \mathrm{I}^{-131 \mathrm{~m}} \mathrm{Xe}$ & $2.7 \times 10^{-4}$ & $184 \mathrm{~h}$ & $9.9 \times 10^{-6}$ & 2.6 & $7.1 \times 10^{-4}$ & $5.1 \times 10^{-5}$ \\
\hline${ }^{110 m} \mathrm{Ag}^{-110} \mathrm{Ag}$ & $2.7 \times 10^{-5}$ & $118 \mathrm{~h}$ & $6.4 \times 10^{-5}$ & 10.9 & $2.9 \times 10^{-4}$ & $2.1 \times 10^{-5}$ \\
\hline${ }^{111} \mathrm{Ag}$ & $7.3 \times 10^{-5}$ & $72 \mathrm{~h}$ & $1.1 \times 10^{-5}$ & 1.1 & $8.3 \times 10^{-5}$ & $5.9 \times 10^{-6}$ \\
\hline${ }^{198} \mathrm{Au}$ & $7.6 \times 10^{-6}$ & $62 \mathrm{~h}$ & $1.4 \times 10^{-5}$ & 1.3 & $9.7 \times 10^{-6}$ & $6.9 \times 10^{-7}$ \\
\hline${ }^{199} \mathrm{Au}$ & $2.1 \times 10^{-5}$ & $74 \mathrm{~h}$ & $5.3 \times 10^{-6}$ & 0.56 & $1.2 \times 10^{-5}$ & $8.6 \times 10^{-7}$ \\
\hline${ }^{186} \mathrm{Re}$ & $5.5 \times 10^{-4}$ & $59 \mathrm{~h}$ & $1.1 \times 10^{-5}$ & 0.90 & $5.0 \times 10^{-4}$ & $3.6 \times 10^{-5}$ \\
\hline${ }^{188} \mathrm{Re}$ & $1.3 \times 10^{-2}$ & $15 \mathrm{~h}$ & $2.4 \times 10^{-5}$ & 0.53 & $6.9 \times 10^{-3}$ & $5.0 \times 10^{-4}$ \\
\hline${ }^{67} \mathrm{Ga}$ & 1000 & $51 \mathrm{~h}$ & $3.0 \times 10^{-6}$ & 0.22 & 220 & 1 \\
\hline${ }^{65} \mathrm{Zn}$ & $2.5 \times 10^{-4}$ & $194 \mathrm{~d}$ & $6.1 \times 10^{-6}$ & 41 & 0.010 & $4.5 \times 10^{-5}$ \\
\hline${ }^{111} \operatorname{In}$ & 1000 & $63 \mathrm{~h}$ & $5.8 \times 10^{-6}$ & 0.53 & 530 & 1 \\
\hline${ }^{109} \mathrm{Cd}-{ }^{109 m} \mathrm{Ag}$ & $8.1 \times 10^{-3}$ & $139 \mathrm{~d}$ & $3.2 \times 10^{-6}$ & 15 & 0.12 & $2.3 \times 10^{-4}$ \\
\hline${ }^{114 \mathrm{~m}} \mathrm{In}^{-114} \mathrm{In}$ & 0.75 & $25 \mathrm{~d}$ & $2.9 \times 10^{-5}$ & 25 & 19 & 0.036 \\
\hline${ }^{201} \mathrm{Tl}$ & 1000 & $46 \mathrm{~h}$ & $2.6 \times 10^{-6}$ & 0.17 & 170 & 1 \\
\hline${ }^{65} \mathrm{Zn}$ & $3.0 \times 10^{-5}$ & $194 \mathrm{~d}$ & $6.1 \times 10^{-6}$ & 41 & $1.2 \times 10^{-3}$ & $7.1 \times 10^{-6}$ \\
\hline${ }^{202} \mathrm{Tl}$ & 4.4 & $84 \mathrm{~h}$ & $6.0 \times 10^{-6}$ & 0.74 & 3.2 & 0.019 \\
\hline${ }^{123} \mathrm{I}$ & 1000 & $13 \mathrm{~h}$ & $3.1 \times 10^{-6}$ & 0.058 & 58 & 1 \\
\hline${ }^{22} \mathrm{Na}$ & $6.3 \times 10^{-3}$ & $11 \mathrm{~d}$ & $2.8 \times 10^{-5}$ & 11 & 0.067 & $1.2 \times 10^{-3}$ \\
\hline${ }^{121} \mathrm{Te}$ & 0.13 & $8.0 \mathrm{~d}$ & $6.5 \times 10^{-6}$ & 1.8 & 0.23 & $4.0 \times 10^{-3}$ \\
\hline${ }^{124} \mathrm{I}$ & 56 & $4.1 \mathrm{~d}$ & $1.8 \times 10^{-5}$ & 2.6 & 143 & 2.5 \\
\hline${ }^{125} \mathrm{I}$ & 2.0 & $42 \mathrm{~d}$ & $1.7 \times 10^{-6}$ & 2.5 & 4.9 & 0.085 \\
\hline${ }^{126} \mathrm{I}$ & 2.5 & $12 \mathrm{~d}$ & $9.3 \times 10^{-6}$ & 3.8 & 9.6 & 0.17 \\
\hline${ }^{81 \mathrm{~m}} \mathrm{Kr}$ & 1000 & $*$ & $3.7 \times 10^{-6}$ & $3.1 \times 10^{-5}$ & 0.031 & 1 \\
\hline${ }^{79} \mathrm{Kr}$ & 0.45 & $*$ & $6.1 \times 10^{-6}$ & $5.1 \times 10^{-5}$ & $2.3 \times 10^{-5}$ & $7.4 \times 10^{-4}$ \\
\hline${ }^{81} \mathrm{Rb}-{ }^{81 \mathrm{~m}} \mathrm{Kr}$ & 0.17 & $35 \mathrm{~h}$ & $1.3 \times 10^{-5}$ & 0.084 & $1.4 \times 10^{-2}$ & 0.45 \\
\hline${ }^{82 \mathrm{~m}} \mathrm{Rb}^{-82} \mathrm{Rb}$ & $1.1 \times 10^{-2}$ & $6.3 \mathrm{~h}$ & $2.9 \times 10^{-5}$ & 0.264 & $2.9 \times 10^{-3}$ & 0.094 \\
\hline${ }^{83} \mathrm{Rb}-{ }^{83 \mathrm{~m}} \mathrm{Kr}$ & $4.9 \times 10^{-6}$ & $30 \mathrm{~d}$ & $2.8 \times 10^{-6}$ & 2.86 & $1.4 \times 10^{-5}$ & $4.5 \times 10^{-4}$ \\
\hline${ }^{197} \mathrm{Hg}$ & 1000 & $51 \mathrm{~h}$ & $3.1 \times 10^{-6}$ & 0.23 & 230 & 1 \\
\hline${ }^{203} \mathrm{Hg}$ & 3.3 & 39 & $5.5 \times 10^{-6}$ & 0.31 & 1.0 & $4.3 \times 10^{-3}$ \\
\hline${ }^{60} \mathrm{Co}$ & $1.9 \times 10^{-5}$ & $228 \mathrm{~h}$ & $2.7 \times 10^{-5}$ & 8.9 & $1.9 \times 10^{-4}$ & $8.3 \times 10^{-7}$ \\
\hline${ }^{65} \mathrm{Zn}$ & $2.4 \times 10^{-5}$ & $194 \mathrm{~d}$ & $6.1 \times 10^{-6}$ & 41 & $9.8 \times 10^{-4}$ & $4.3 \times 10^{-6}$ \\
\hline${ }^{110 \mathrm{~m}} \mathrm{Ag}^{-110} \mathrm{Ag}$ & $6.5 \times 10^{-6}$ & $120 \mathrm{~h}$ & $6.4 \times 10^{-5}$ & 11 & $7.1 \times 10^{-5}$ & $3.1 \times 10^{-7}$ \\
\hline
\end{tabular}




\begin{tabular}{|c|c|c|c|c|c|c|c|}
\hline Nuclide & $\begin{array}{c}\text { Relative } \\
\text { activity }(\mu \mathrm{Ci})\end{array}$ & $\begin{array}{r}\text { Effe } \\
\text { hal }\end{array}$ & $\begin{array}{l}\text { tive } \\
\text {-life }\end{array}$ & $\begin{array}{c}S \text {-value } \\
(\mathrm{rad} / \mu \mathrm{Ci} \mathrm{h})\end{array}$ & $\begin{array}{l}\text { Absorbed dose } \\
(\mathrm{mrad} / \mu \mathrm{Ci})\end{array}$ & $\begin{array}{l}\text { Absorbed dose } \\
\text { (mrad) }\end{array}$ & Relative \\
\hline${ }^{75} \mathrm{Se}$ & 1000 & 242 & $\mathrm{~h}$ & $4.6 \times 10^{-6}$ & 1.6 & 1600 & 1 \\
\hline${ }^{110 \mathrm{~m}} \mathrm{Ag}-{ }^{-110} \mathrm{Ag}$ & $1.2 \times 10^{-4}$ & 118 & $\mathrm{~h}$ & $6.4 \times 10^{-5}$ & 11 & $8.2 \times 10^{-4}$ & $5.1 \times 10^{-7}$ \\
\hline${ }^{198} \mathrm{Au}$ & 1000 & 62 & $\mathrm{~h}$ & $1.4 \times 10^{-5}$ & 1.3 & 1300 & 1 \\
\hline${ }^{110 \mathrm{~m}} \mathrm{Au}{ }^{-110} \mathrm{Ag}$ & $8.4 \times 10^{-4}$ & 118 & $\mathrm{~h}$ & $6.3 \times 10^{-5}$ & 11 & $9.2 \times 10^{-3}$ & $7.1 \times 10^{-6}$ \\
\hline${ }^{192} \mathrm{Ir}$ & $2.4 \times 10^{-4}$ & 379 & $\mathrm{~h}$ & $1.5 \times 10^{-5}$ & 8.0 & $1.9 \times 10^{-3}$ & $1.5 \times 10^{-6}$ \\
\hline${ }^{196} \mathrm{Au}$ & $1.7 \times 10^{-2}$ & 142 & $\mathrm{~h}$ & $5.1 \times 10^{-6}$ & 1.0 & $1.7 \times 10^{-2}$ & 1. $3 \times 10^{-5}$ \\
\hline${ }^{199} \mathrm{Au}$ & 106 & 74 & $\mathrm{~h}$ & $5.3 \times 10^{-6}$ & 0.56 & 60 & $4.7 \times 10^{-2}$ \\
\hline
\end{tabular}

\section{4. 結 び}

主な放射性医薬品の不純物核種の測定結 果をもと に, 不純物核種による内部被曝線量への寄与を計算に よって評価した。内部被曝線量は MIRD 法に従って 計算した。ここで体内に摄取された RI は全身に均等 に分布するものとし，線源臓器および標的臓器ともに 全身とした。

不純物核種による内部被曝線量への寄与は ${ }^{123} \mathrm{I} て ゙$ 目 的核種のおよそ $280 \%$ 最も高く， ${ }^{81 \mathrm{~m}} \mathrm{Kr}$ で55\%， ${ }^{198} \mathrm{Au}$ で5\%， ${ }^{111} \mathrm{In}$ で 4\%， ${ }^{201} \mathrm{Tl}$ で $2 \%$ ，その他の核種は $1 \%$ 以下であった。

以上の結果から，サイクロトロンで製造される核種 は，一般に不純物の混入濃度が比較的高く，これによ る被曝線量も無視できないため，放射性医薬品による 内部被曝線量の評価などのさいには，不純物の寄与を 考慮する必要がある。

\section{文献}

1）橋詰 雅, 丸山隆司, 山口 寛, 他 : 日医放会 誌，39，747-760 (1979)

2）科学技術庁原子力安全局編：「放射 線 利 用 統 計」，日本アイソトープ協会 (1984)

3）三枝健治，筧 弘毅：Radioisotopes，25，60 $-70(1976)$

4) Colemzetti, L.G. and Barnes, W.E.: Int. J. Appl. Radiat. Isot., 25, 455-461 (1974)

5）天野良平, 森 厚文, 真田 茂, 他：核医学, 17, 601-606 (1980)

6）森 厚文, 天野良平, 安東 醇, 他: 同上, 17, 723-728 (1980)

7) 武藤利雄：Radioisotopes, 31, 591-594(1982)

8）武藤利雄：ibid., 34, 162-165（1985）
$(1 \mu \mathrm{Ci}=37 \mathrm{kBq}, 1 \mathrm{rad}=0.01 \mathrm{~Gy}, 1 \mathrm{mrad}=0.01 \mathrm{mGy})$

9）武藤利雄 : 昭和59年度東京都立アイソトープ総 合研究所年報, pp. 4-8 (1985)

10) MIRD Committee: MIRD Pamphlet No. 1-6 (1968 - 1970)

11) MIRD Committee: MIRD Pamphlet No. 11 (1975)

12) ICRP Publication 2: "Recommendations of International Commission on Radiological Protection Report of Committee II on Permissible Dose for Internal Radiation", Pergamon Press, New York (1960)

13) NCRP Report No. 58, “A Handbook of Radioactivity Measurements Procedures", National Council on Radiation Protection and Measurements, Washington (1978)

\section{Abstract}

Evaluation of Additional Absorbed Radiation Dose from Radioactive Impurities in Radiopharmaceuticals. Toshio MUTO: Tokyo Metropolitan Isotope Research Center, 11-1, Fukazawa 2-chome, Setagaya-ku, Tokyo 158.

The additional absorbed radiation doses to total body from radioactive impurities in radiopharmaceuticals were estimated for a total of 10 samples (i.e., ${ }^{89 \mathrm{~m}} \mathrm{Tc}$ generator eluates, ${ }^{89 \mathrm{~m}} \mathrm{Tc}$ solutions, ${ }^{67} \mathrm{Ga}$, ${ }^{81 \mathrm{~m}} \mathrm{Kr}$ generator eluates, ${ }^{111} \mathrm{In},{ }^{123} \mathrm{I},{ }^{201} \mathrm{Tl},{ }^{75} \mathrm{Se},{ }^{197} \mathrm{Hg}$, $\left.{ }^{198} \mathrm{Au}\right)$ selected from commonly used radiopharmaceuticals. The radioactive impurities in radiopharmaceuticals used in this estimation were previoulsy identified. The radiation doses were calculated according to the MIRD procedures, assuming each radionuclide to be uniformly distributed throughout the body. In the case of the cyclotron-produced radioisotopes and ${ }^{198} \mathrm{Au}$, the additional total body absorbed doses from impurities were found to be rather high: $280 \%$ for ${ }^{123} \mathrm{I}, 55 \%$ for ${ }^{81 \mathrm{~m}} \mathrm{Kr}, 5 \%$ for ${ }^{198} \mathrm{Au}, 4 \%$ for ${ }^{111} \mathrm{In}$ and $2 \%$ for ${ }^{201} \mathrm{Tl}$. The absorbed doses due to impurities in the other radioisotopes were less than $1 \%$.

(Received February 5, 1986) 